\title{
SPATIOTEMPORAL EVALUATION OF NOCTURNAL COLD AIR DRAINAGE OVER A SIMPLE SLOPE USING THERMAL INFRARED IMAGERY
}

\author{
V. Ikani ${ }^{\text {a }}{ }^{*}$, K. Chokmani ${ }^{\text {b }}$, L. Fathollahi ${ }^{\text {c }}$, H. Granberg ${ }^{\text {a }}$, R .Fournier ${ }^{\text {a }}$ \\ ${ }^{\text {a }}$ Department of Applied Geomatics, Centre for research and applications in remote sensing (CARTEL), University of Sherbrooke, \\ Québec, Canada - (Vahid.Ikani, Hardy.Granberg, Richard.Fournier)@Usherbrooke.ca \\ ${ }^{\mathrm{b}}$ Institut National de la Recherche Scientifique (INRS) - Eau Terre Environnement Research Centre, Québec, Canada, \\ karem.chokmani@ete.inrs.ca \\ ${ }^{\mathrm{c}}$ Boukan, Meteorological Station - West Azerbaijan, Iran, fathollahi.loghman @ gmail.com
}

Commission WG VIII3- Weather, Atmosphere and Climate studies

KEY WORDS: Infrared camera, Cold air drainage velocity, Cooling rates, Cold air pooling, Microclimate, Radiation frost

\begin{abstract}
:
Measurements of climatic processes such as cold air drainage flows are problematic over mountainous areas. Observation of cold air drainage is not available in the existing observation network and it requires a special methodology.

The main objective of this study was to characterize the cold air drainage over regions with a slope. A high resolution infrared camera, a meteorological station and Digital Elevation Model (DEM) were used. The specific objective was to derive nocturnal cold air drainage velocity over the slope. To address these objectives, a number of infrared measurement campaigns were conducted during calm and clear sky conditions over an agricultural zone (blackcurrant farm) in Canada.

Using thermal infrared images, the nocturnal surface temperature gradient were computed in hourly basis. The largest gradient magnitudes were found between $17 \mathrm{~h}-20 \mathrm{~h}$. The cooling rates at basin area were two times higher in comparison to the magnitudes observed within slope area. The image analysis illustrated this considerable temperature gradient of the basin may be partly due to transport of cold air drainage into the basin from the slope.

The results show that thermal imagery can be used to characterize and understand the microclimate related to the occurrence of radiation frost in the agricultural field. This study provided the opportunity to track the cold air drainage flow and pooling of cold air in low lying areas. The infrared analysis demonstrated that nocturnal drainage flow displayed continuous variation in terms of space and time in response to microscale slope heterogeneities. In addition, the analysis highlighted the periodic aspect for cold air drainage flow.
\end{abstract}

\section{INTRODUCTION}

Measurements of climatic processes such as cold air drainage flows are problematic over mountainous areas due to the influence of orography and the lack of spatiotemporal climatic data. It is not forthcoming from the existing observation network and requires a special methodology. Cooling during the night caused by radiation is the reason that cold air from mountains and slope descend under gravity into valley or basin air fills cold air reservoir (fohn 2006). In general, down slope movement of air is referred to as katabatic wind. The local down slope gravity flow are called air drainage (Bergen 1969), cold air runoff, (Geiger 1965) or cold air flow (Geiger 1965). Cold air drainage flows have been observed on slopes as small as $1 \%$ (Soler et al.2002), and this flow is usually laminar (i.e., stratified or poorly mixed) because of the strong stability in the flow.

Thermally driven flows over simple slopes are a relevant research topic, not only per se, but also as a source of key concepts for understanding and modelling many other flows over more complex topographies. Various studies have documented the persistence of the drainage flow pattern (Fleagle 1950, Yashino 1968, Whiteman and Zhong, 2008). Air drainage has received attention from both the observational and theoretical points of view.
Observational work has largely focused on identifying flow patterns and investigating possible corrections to eddycovariance flux measurements. There has been less emphasis on causes of, or influences on, flow development.

Udea et al (2003) observed spatial pattern of surface temperature on clear weather condition using an infrared thermal imager. Thermal image analysis reveals that frequent formation of strong nocturnal cooling after late summer lowered surface temperature.

An infrared thermography used by Hori and Watarai (2005) in the Sothern slope Mt Houkyou and accompanying slopes holding a quarry where vegetation is scarce. Based on thermography analysis it was found that the cooling rate over open slop is higher than the slope covered with vegetation.

One of the most recent researches to use thermal imagery has done by Grudzielanek and Cermak (2015). A measurement setup consisting of an infrared camera and a projection screen was designed to measure microscale cold-air flow on sloping grassland. Analyses of cold-air-flow characteristics including vertical temperature profiles of near-surface cold-air flows obtained from the thermal camera analysis are presented. In addition high temporal resolution of data collection becomes was highlighted. In agro meteorology field, in order to analyzing and improving cold air drainage Ikani et al (2015) used thermal infrared camera to assess the thermal

\footnotetext{
${ }^{*}$ Corresponding author : vahid.ikani@Usherbrooke.ca
} 

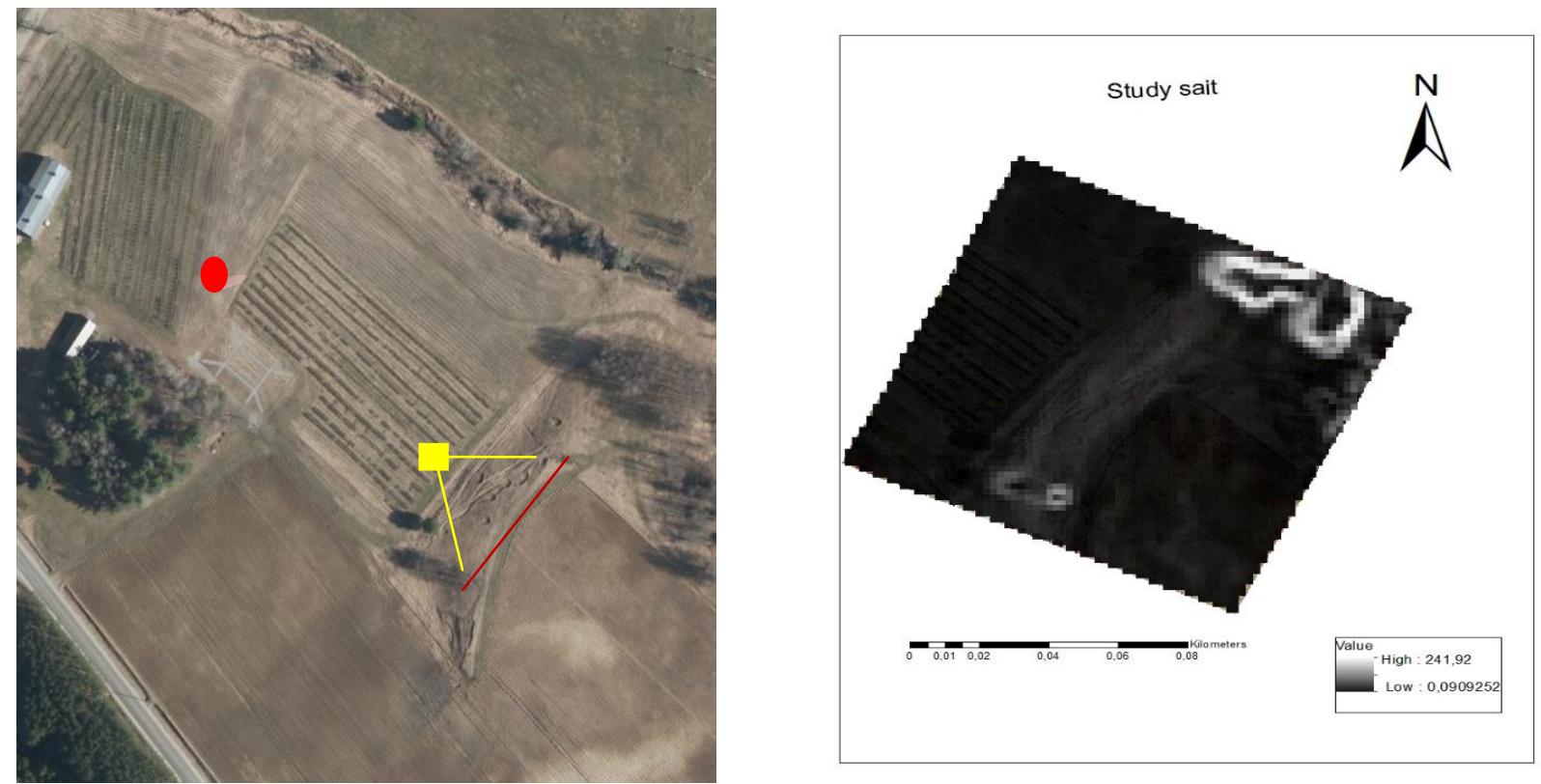

Figure 1, Show aerial photography (left figure) of the study area and the position of locations of Camera and station meteorology that provided data. The right figure is DEM image of study area.

heterogeneity quantitatively with a high resolution in an orchard in Quebec, Canada.

Despite the wide array of measurement and modelling approaches available, it has not been possible to date to analyze near-surface cold-air flow coherently at high spatial and temporal resolutions without the need to interpolate isolated measurements. Improving the understanding of the controls of spatial variability of temperature is a necessary goal for improved modeling, such as mesoscale meteorology.

Therefore, the main objective of this research was to characterize the cold air drainage over regions with a slope with a high resolution. The specific objective was to derive nocturnal cold air drainage velocity over the slope.

\section{METHODOLOGY}

\subsection{Site and data description}

To address these objectives a number of infrared measurement campaigns are conducted particularly during calm, clear sky conditions where late radiation frosts occurred. Study site was an agricultural zone (blackcurrant farm) south of Quebec,

Canada.

Figure 1(a) shows the field of observation. The location of metrological station and camera are show by red and yellow colors respectively. View is from observational point by camera are and slope ridge are presented by yellow and red lines respectively. Figure 1(b) show topographic map derived from DEM.
The instrument used in the observation is an infrared thermography Detection range of the instrument is $-50{ }^{\circ} \mathrm{C} 200$ ${ }^{\circ} \mathrm{C}$ with minimum temperature interval of 0.05 . Each thermal image is raster scanned into a grid of $479 * 639$ Lines .Degital elevation model at a resolution $10 \mathrm{~m}$ was employed to calculate topographic parameter.

\subsection{Quantitative infrared thermography}

Several expressions have been developed for estimating the wind speed associated with slope drainage. The strength of the katabatic wind can be determined from the temperature difference between the cold air flowing downslope and the surrounding area. Applying a local equilibrium between buoyancy / suppression and stress the velocity of the katabatic flow is (Stull 2000).

$$
u_{k}=\left[\frac{g \cdot\left(T-T_{k}\right)}{T} \cdot \frac{h}{C_{D}} \cdot \sin a\right]^{1 / 2}
$$

$h$ is the depth of the cold air layer, $C D$ is the drag coefficient, $\alpha$ is the angle of inclination of the slop, $g$ is the acceleration due to gravity, $T$ is the surrounding air temperature, and $T K$ is the temperature of the cold air layer. In this research the cold air drainage velocity was estimated using equation 1. Accordingly, Digital Elevation Model (DEM) and data are integrated with point-based meteorological data and thermal infrared imagery. 


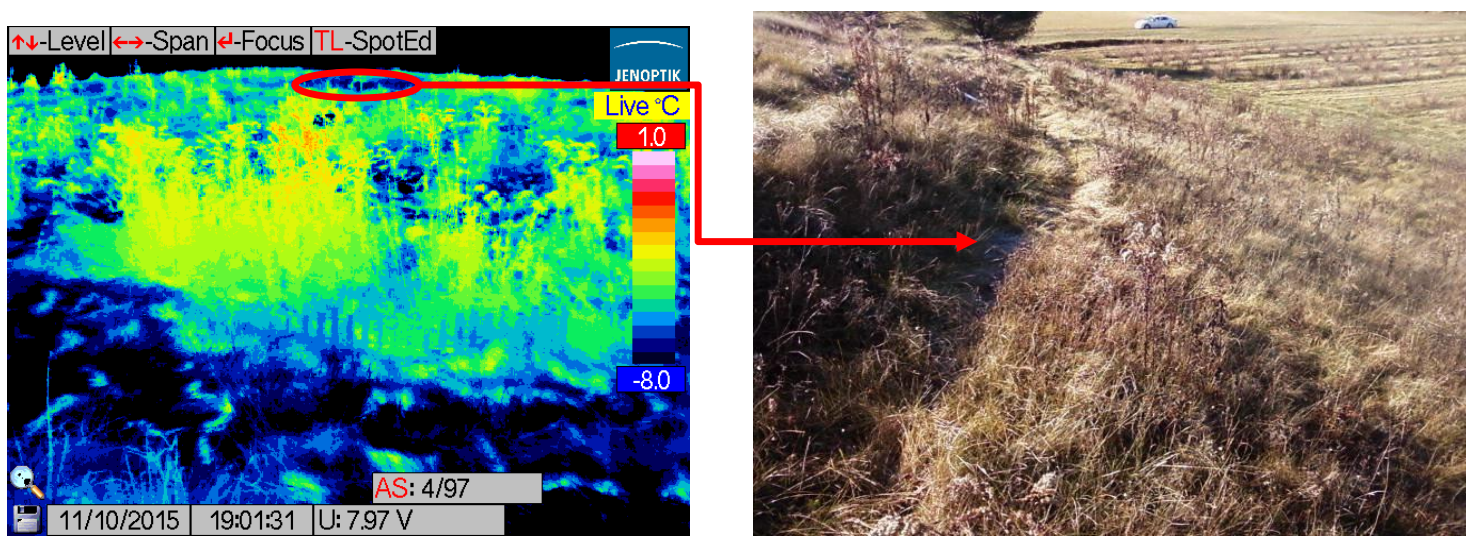

Figure 2 (a) spatial variability of surface temperature, figure 2 (b) show the area prone to frost hollow and cold air pockets

\section{RESULTS}

\subsection{Infrared thermal imaging the air flow: qualitative aspect}

As the figure 2 show Thermal images analysis demonstrated and located the area prone to frost hollow and cold air pockets. The experimental study also inspected the periodic aspect of drainage moving along the slope. The results indicated that the differences between microscale topography and vegetation cover were the keys factors to determine the spatial pattern of nocturnal surface temperature. In addition figure 2, shows heterogeneous nocturnal cooling over the simple slope. The result of this part indicate the importance of microtopograpic and land cover their general applicability in exploring microscale temperature variation .It should be noted that figure 2 demonstrates and locates the area prone to frost hollow and cold air pockets due to microtopography .

\subsection{Spatial -temporal variation of surface temperature}

Using thermal infrared images the hourly surface temperature gradient temperature ware calculated and presented by figure 3 . As the figure illustrate largest gradient magnitudes were found between 20-17 h. In addition the figure show clearly temperature gradient over basin area were two times $\left(2{ }^{\circ} \mathrm{C}\right)$ higher in comparison to the magnitudes observed within slope area $\left(.5^{\circ} \mathrm{C}\right)$. The image analysis shows this rapid cooling of the basin that may be partly due to transport of cold air drainage into the basin from the slope.

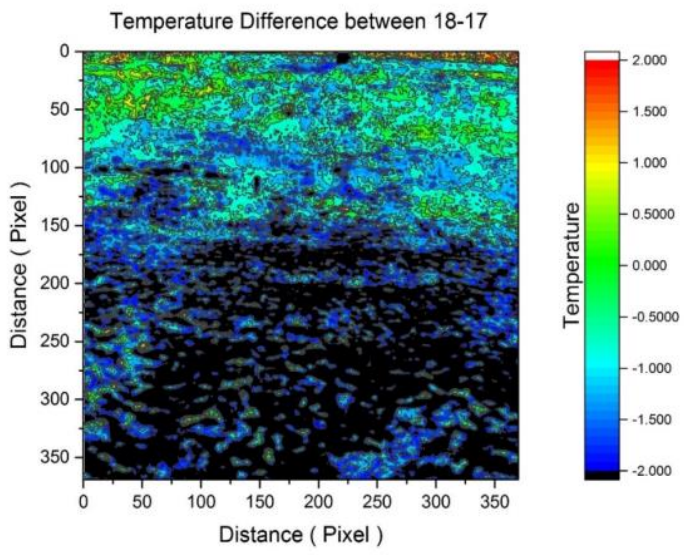

Figure 3 (a) Temparature diference between $18 \mathrm{~h}-17 \mathrm{~h}$

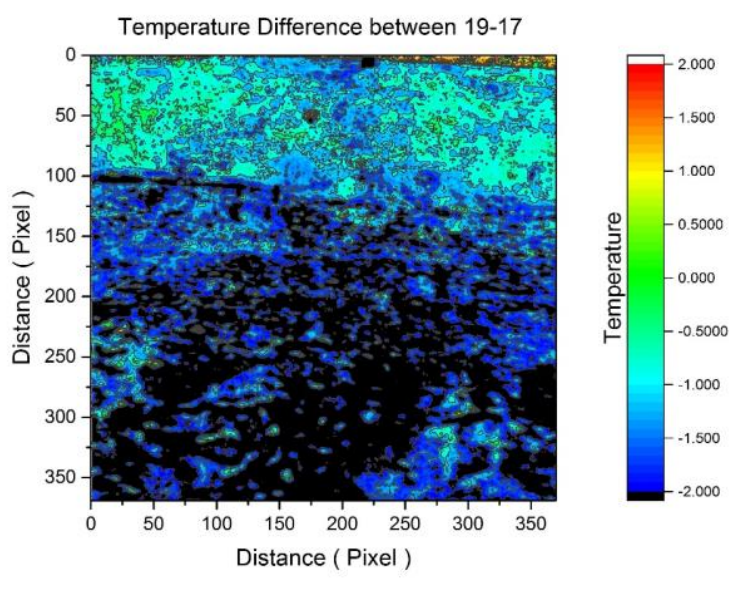

Figure 3 (b) Temparature diference between 19h-17h

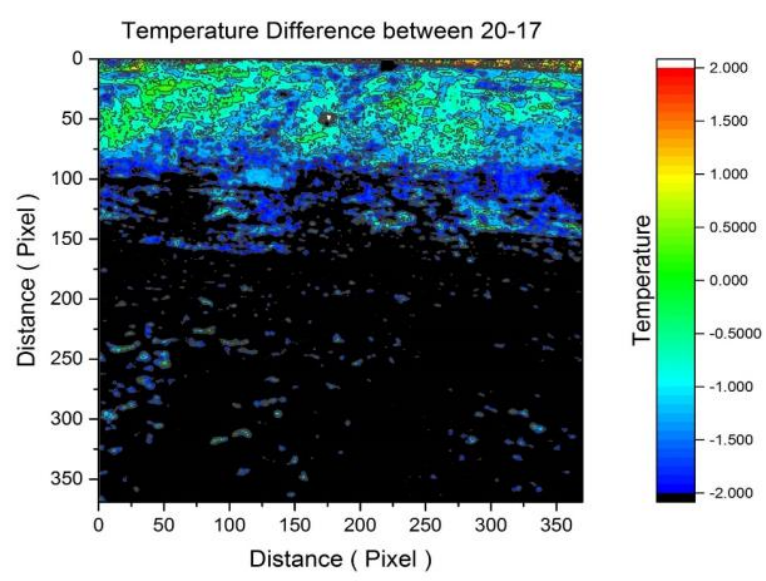

Figure 3 (c) Temparature diference between 20h-17h

\subsection{Periodic aspects of drainage moving}

Analysis of thermal images also inspected the periodic aspect for drainage moving along the slope. It showed cold air movement was not continual. Conversely, after cold air finished passing the slope, some extra time was needed to 
trigger the next pulse of sloping flow. Figure 4 shows development cold air over the slope. Red color show cold air drainage. At 20:50:08 there was not the cold air drainage on slope area (covered by blue). At 20:56:14 there is no blue area. It was covered by the red (cold air drainage). Finally at 21:02:26 slope was covered again by the blue.

\subsection{Mean wind velocity estimated}

Based on the combination data of Digital Elevation Model (DEM), infrared imagery and meteorological station the mean velocity fields of nocturnal downslope flows were derived. The results indicate that through the evening transition time, the velocity reaches the maximum $(0.13 \mathrm{~m} / \mathrm{s})$. It decreases slightly and approaches a constant value $(0.09 \mathrm{~m} / \mathrm{s})$ until morning transition time.

\section{CONCLUSION}

In conclusion, this study illustrated that the thermal infrared camera can be considered as a powerful tool to assess the thermal heterogeneity quantitatively with high resolution.it can be used to characterize and understand the microclimate related

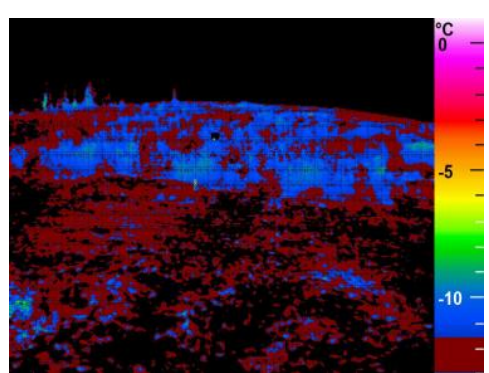

a) 20:50:08

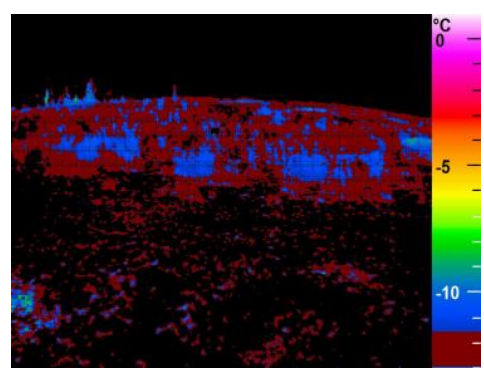

d) $20: 55: 44$

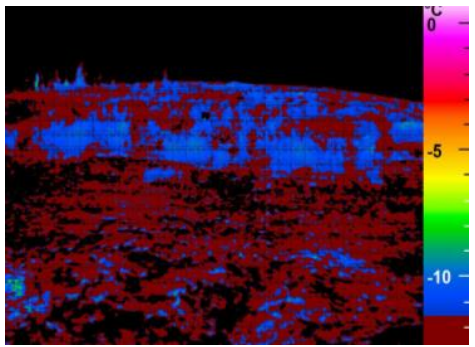

g) $21: 02: 26$

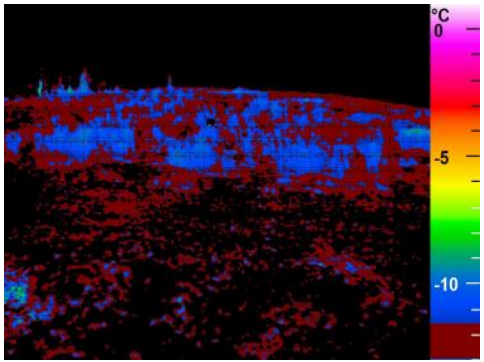

b) $20: 51: 40$

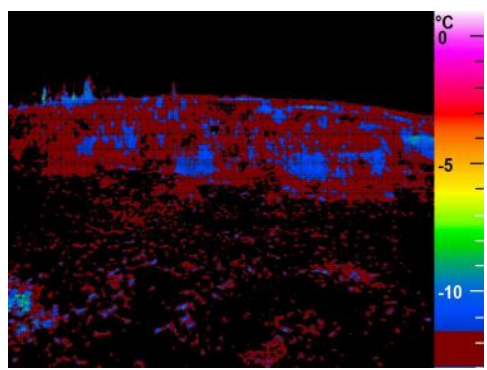

e) 20:56:14

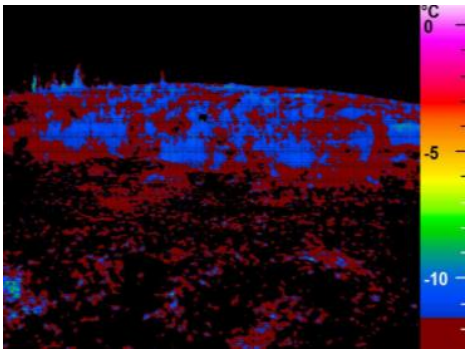

h) $21: 06: 50$

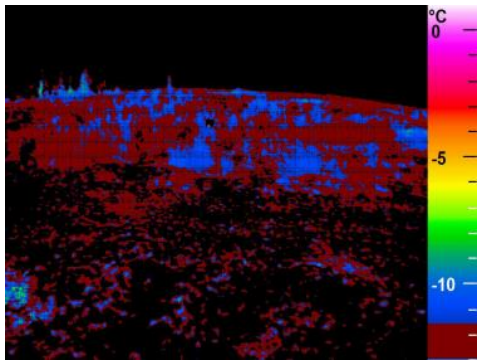

c) $20: 52: 26$

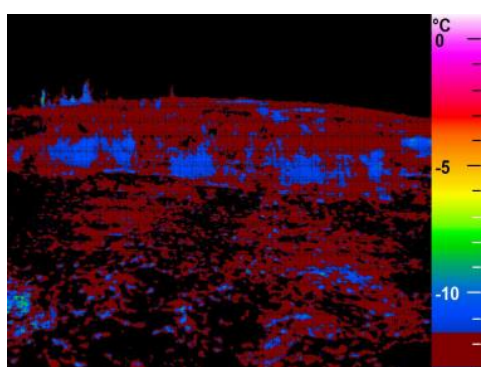

f) $21: 01: 02$

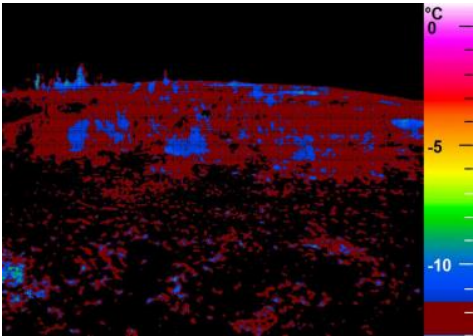

i) 21:08:04

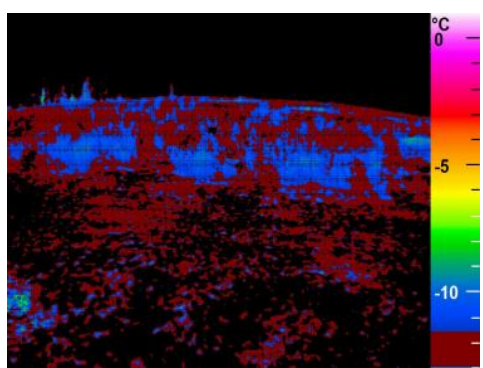

j) $21: 12: 54$

Figure 4. (a,b,c...j) illustrated periodic aspect of cold air drainage over the slope for example at 21:2:26 there is no drainage (blue color) ,at 21:8:04 slope is cover by darniage (red color) 
to the occurrence of radiation frost in the agricultural field. This study provided the opportunity to track the cold air drainage flow and pooling of cold air in low lying areas. The infrared analysis demonstrated that nocturnal drainage flow displayed continuous variation in terms of space and time in response to microscale slope heterogeneities. In addition, the analysis highlighted the periodic aspect for cold air drainage flow.

\section{REFERENCES}

Fleagle, R. G., 1950. A theory of air drainage, Journal of Meteorology, Vol.7, pp 227-232

Foken, T., Nappe, C., 2008. Micrometeorology, Springer, p, $308 \mathrm{p}$.

Geiger, R., 1965. The Climate near the Ground, Harvard University Press, 437 p.

Grudzielanek, M., Cermak. j., 2015. Analysis of katabatic flow using infrared imaging, Boundary-Layer Meteorology, November 2015, Volume 157, Issue 2, pp 321-332

Hori. E. and Watari.Y ., 2005, Observation of thermal belt on an open slope by use of infrared thermography Tsukuba Geoenvironmental Sciences, Vol. 1, pp. 3-10

Ikani.V., Chokmani .K, Turcotte.C ., 2015. Analyse de l'accumulation de l'air froid en milieu agricole par imagerie thermique, XVIe Congrès de l'Association québécoise de télédétection (AQT), Québec, Canada

Stull, R. B., 2000. Meteorology for Scientists and Engineers, Brooks/Cole, 2000 - 502 pages

Soler, M. Infante,P., Mahrt. L., 2002. Observations of nocturnal drainage flow in a shallow gully, Boundary-Layer Meteorology V.105. pp. 253-273.

Ueda, H., Hori, M., Nohara, D., 2003. Observational study of the thermal belt on the slope of Mt. Tsukuba. J. Meteor. Soc. Japan, 81, 1283-1288.

Whiteman, C. D. and Zhong, S. 2008. Downslope flows on a low-angle slope and their interactions with valley inversions. Part I: observations'. Appl. Meteorol. Clim. 47, 2023-2038.

Yoshino, M.M., 1968. Problems in local and micrometeorology in relation to agriculture in Japan, Agroclimatologicalmethods: Proceedings of the Reading Symposium.UNESCO, Reading, UK, pp. 269-280 